\title{
The Speech Act of Apology by Filipino Call Center Agents
}

Mary Joy V. Sienes ${ }^{1 *}$, Jasper Eric C. Catan ${ }^{1}$

${ }^{1}$ Silliman University, Philippines

*Corresponding author's email: maryvsienes@su.edu.ph

* Orcid: https://orcid.org/0000-0003-2921-5315

DOI: https://doi.org/10.54855/ijte.22218

The Philippines is a global leader in business process outsourcing (BPO). Many foreign investors view the Philippines as a viable location for their call center operations due to the Filipinos' strength in English proficiency. This study focuses on inbound call center accounts that deal with a variety of call situations, ranging from information requests to difficult calls that require more time to handle, such as complaint calls. Since the goal of any business is customer satisfaction, this research aims to investigate how Filipino call center agents mitigate and reduce the liability and guilt towards customers. Results show that the 90 call center representatives have successfully produced 'perfect apologies' by providing all five strategies posited by Cohen et al. (1986) in most of their complaint

Keywords: speech act, apology, call center, BPO, communication calls. However, the sequence is distorted by emphasizing more on offering a repair. This leads to a recommendation that calls center training on apology be emphasized on building personal connections rather than a mechanical response to situations.

\section{Introduction}

"I am sorry to hear that."

This statement summarizes the daily interaction experiences of the call center agents handling inbound complaints calls. How well a call center agent can deal with an irate customer may be influenced by the agent's ability to communicate and carry out a language function called apologizing.

Communication is an interesting area of research since studying communication does not only help people succeed professionally through strong oral and written communication skills but also helps develop life skills such as conflict resolution and critical thinking. It improves understanding of others and builds or even destroys relationships (McGaan, 2010). Another reason for studying communication is any register shifts brought by culture change. Despite a strict rule when to use formal language and informal language at work, the latter has infiltrated 
even the dealings and transactions between the client and the associate. This study draws particular interest in conversations between call center agents and their clients. It was revealed that some call center representatives in the United States failed to show empathy to their clients whenever there were complaints. They further argued that choosing the right words would help the representatives express their empathy to their clients (Bowens \& Cook, n.d.). Since English, being an international language, is used as the medium of communication, it embodies a variety of cultures, and it cannot be used without a thorough understanding of its own relationships, identities, and experiences (Pham, N. T. L. (2021). Most of the time, choosing the right words is dependent on the feelings of both the speaker and the listener. Informal language is usually preferred when the situation calls for a more relaxed, casual, and spontaneous conversation ("Formal and Informal Language," 2020). Call centers typically have to deal with angry, dissatisfied, and irate clients. Call enter agents are trained to always be in control of the situation. At these times, despite the formal nature of the call center business, informal language in speaking is always seen to help alleviate emotional encounters with clients.

According to Cabigon (2015), the Philippines is one of the largest English-speaking nations where the majority of the constituents can speak English. Furthermore, the proficiency of the Filipinos in the English language is one of the significant factors that made the Philippines the top voice outsourcing destination in the world. However, there is a greater need to enhance the English skills of the labor force, particularly those in the business process outsourcing (BPO) sector, to maintain the proficiency strength of the Philippines. As emphasized by Nishanthi (2018) in (Luu Le Phuong Thanh et al., 2021), English has become an international language and is widely spoken around the world. Thus, individuals must enhance their communication abilities in order to be successful in their chosen industries.

The main goal of any customer support service is customer satisfaction. The ability of customer support to handle dissatisfied and even furious customers can greatly affect any business. According to Porteous (2020), "customer service is the be-all and end-all of good business." In public service, a complaint and an apology are essential for customer service, and employees must understand the impact of the client's perception (Belfas \& Musyahda, 2015). Thus, it is crucial to understand the apology strategies used by call center agents in handling customer complaints. In this study, the researchers aim to investigate the apology strategies used by the Filipino call center agents, explore the apology patterns used by the Filipino call center agents in receiving complaint calls, and identify effective semantic formulas in making felicitous apology acts. Specifically, this study seeks to answer the following questions:

- What are the dominant semantic classifications of apology strategies manifested in the DCT of the respondents?

- What are the prevailing patterns of semantic formulas observed after classifying the apology strategies used? 


\section{Theoretical Background}

This study focuses on the speech act of apology. It is anchored on Speech Act Theory by Austin (1962) and Searle (1969). The data are coded and analyzed using Prachanant's (2006) Apology Strategies. The other apology taxonomies that helped the researchers in the conceptualization of this research are also discussed below. Because English has become an international language and is widely spoken around the world, individuals must enhance their communication abilities in order to be successful in their chosen industries.

\section{Speech Act Theory}

The words people utter in a speech situation are not only words and mere syntactic structures; they are thoughts, ideas, and emotions. In everyday communication, the words and phrases used by interlocutors perform certain language functions such as greeting, complimenting, ordering, thanking, apologizing, complimenting, among others, called speech acts (Sienes, 2019). The speech act theory was developed by John Austin based on a series of lectures, which were compiled in a short book called How to Do Things with Words, released in 1962. John Searle, who added to Austin's views and presented them in a more methodical manner in 1969, expanded on Austin's concepts (Cook, 1989, p. 35).

John Austin (1975) believed that an utterance could be used to perform an act. He pointed out that by uttering a sentence, one can say things and do things. For example, when someone says I'm sorry for the way I acted, the person is not only saying, but he is also apologizing. Parker and Riley $(2010$, p. 8$)$ explained that a speech act has at least two facets: the locutionary act and the illocutionary act. The locutionary act is a description of what the speaker says. It is simply uttering a sentence. A locutionary act is composed of a referring expression with a noun phrase and a predicating expression or a verb phrase. For example, when a customer tells the customer service agent, You must refund my money, the referring expression is you, and the predication expression is must refund my money. On the other hand, an illocutionary act is what the speaker does in uttering a sentence, including acts of stating, requesting, questioning, apologizing, etc. In the example above, You must refund my money, the illocutionary act is ordering.

John Searle (1976 in Parker \& Riley, 2010, p. 9) classified illocutionary acts into different types: representative, directive, question, commissive, expressive, and declaration. The speech act of apology, which is the focus of this study, is categorized by Searle as expressive. An expressive is an utterance used to express the speaker's emotional state. Other acts in this category include thanking, congratulating, condoling, deploring, objecting, among others.

\section{Goffman's (1971) Description of Apology}

Erving Goffman (1971 in Slocum, Allan, \& Allan, 2011) defined apology as a speech act that involves the expression of embarrassment and humiliation. It also involves an act of clarification that one knows what conduct had been expected and an act of sympathy with the 
application of negative sanction such as verbal rejection, repudiation, and denial of the incorrect way of behaving along with self-condemnation. It constitutes the acceptance of the right way and a declaration to do what is right as manifested in performing repair and compensation. As cited by Kort (1975), Goffman described the apology as a "remedial work." Kort explained that remedial work could be a group action that arises from a social rule violation. Its function is to change what can be perceived as offensive into something acceptable. Kort synthesized that "apology, in keeping with Goffman, is one of the three basic ritual devices along with "account" and "request", which can cause transformation. To give an account is to represent oneself as not entirely responsible or is liable to be, thought guilty.

Meanwhile, a request asks a potentially offended person to engage in something that could violate his rights. Both account and request services to keep one's actions from being construed as offensive. However, an apology is a ritual device in which the person splits into two social selves.

Brown (2003) in The Role of Apology in Negotiation mentioned that Goffman explained apology as a process through which a person symbolically splits "into two parts, the part that is guilty of an offense and the part that dissociates itself from the delict and affirms a belief in the offended rule." Gubin (2000) elaborated this by quoting Goffman's words in his book Relations in Public (1971) that says "apologies represent a splitting of the self into a blameworthy part and a part that stands back and sympathizes with the blame giving is by implication, worthy of being brought back into the fold" (p. 2).

Goffman's remedial model (1976) is helpful to understand how call center agents address situations in which the customer always stands at the other side of the spectrum, that is, the one who always has all the rights. In complaint interchanges between the customer and the call center agent, the customer always feels that his rights are violated. It is the customer service representative's role to mediate and fix the "offenses" of the company.

\section{Olshtein \& Cohen's (1983) Classification of Apology}

In this research, Olshtain and Cohen's model (1983 in Olshtain and Cohen, 1990, p. 47) is employed to classify and categorize the apology strategies of the respondents. The categories include expression of apology, acknowledgment of responsibility, explanation, a promise of forbearance, and offer of repair.

Olshtain and Cohen (1990) explained these five strategies, also called semantic formulas, which compose the set of apologies that may be grouped into two: general (expression of apology and acknowledgment) and specific or situation-constraint procedure (explanation, promise of forbearance, and offer of repair). Olshtain and Cohen (1990) elaborated further that "expression of apology and acknowledgment of responsibility use formulaic, routinized apology expressions (I'm sorry, excuse me, I regret, etc.) and therefore, the expression of responsibility reflects the $\mathrm{S}$ 's degree of willingness to admit to fault for $\mathrm{X}$. The first two 
strategies will be used across different situations while explanation, an offer of repair, and the promise of forbearance are situation-specific and will semantically reflect the content of the situation" (p.47).

According to Cohen et al. (1986 in Jones, 2012), apologies often involve one or more of the five verbal strategies. Jones (2012, pp. 104-105) emphasized that

"the 'perfect apology' contains all of these five elements, even when some or most of them are implicit instead of stated outright. For something to possess the 'force' of the apology, however, only one of these strategies is important. In some cases within which only one strategy is employed, however, the speaker leaves it up to the addressee to infer that an apology has been made by relating to the conversational maxims...In many cases, addressees require more than one of the five strategies to be utilized to make the apology complete and sincere."

\section{Prachanant's (2006) Apology Strategies}

In a study conducted by Nawamin Prachanant (2006) in the context of hotel business in Thailand, he focused on occurrences of pragmatic strategies and pragmatic transfer in responding to complaints. Using Olshtain and Cohen's (1983), and Frescura's (1993) taxonomy of apology, Prachanant coded and analyzed the data were gathered through a Discourse Completion Tasks questionnaire (DCTs). Findings of the study revealed that the respondents did not only use the five semantic formulas (Items 1-5 below) originally proposed by Olshtain and Cohen, they also used four other strategies (Items 6-9 below). Thus, it was concluded in Prachanant's study that the personnel in the hotel business around Thailand used the following apology strategies or semantic formulas in responding to complaints: 1) expression of apology, 2) acknowledgment of responsibility, 3) explanation, 4) offering repair, 5) promise of forbearance, 6) making the suggestion, 7) giving the time frame for action, 8) asking for information, and 9) gratitude.

Among these nine strategies, the "offering repair" strategy was employed the most frequently to respond to the complaints among the three groups, followed by "expression of apology" and "acknowledgement of responsibility," respectively.

\section{Methodology}

This study aimed to investigate the semantic expressions and apologizing strategies implored by Filipino call center agents. In order to make this possible, the researchers employed a discourse completion task (DCT) to elicit responses from the respondents on how they usually respond to specific complaint calls. DCT is the only available data collection instrument that generates sufficiently large corpora of comparable, systematically varied speech act data 
(Ogiermann, 2018). There were eight DCT situations in the researcher-made questionnaire based on the suggestions given by the consultants. The DCT situations were synthesized from consultations with three call center directors, their product specialists, and five call center agents with more than two years of work experience to develop valid complaint scenarios.

After all the suggestions were incorporated, the DCTs underwent a review from the administrators, IT security experts, product managers, and international account managers to ensure accountability and reliability of the DCT situations. With the help of the account managers, the DCTs in Google Form were sent to the work emails of the respondents, and the latter was given five to ten minutes to complete the task during their vacant time, before login, or during non-peak hours.

This study implored discourse analysis to code and analyzed the responses of 90 call center agents. Specifically, this study made use of speech act analysis, anchoring the analysis on the following theories:

- Goffman's (1971) Descriptions of Apology

- Olshtein \& Cohen's (1983) Classification of Apology

- Prachanant's (2006) Apology Strategies

The researchers did the coding process, and an encoder tallied the categories. Likewise, the researchers conducted an interview with the CEO of one of the biggest call centers in Asia, who explained the tenets behind the findings of this research. A triangulation of data was conducted through a meeting with the call center management and trainers to present the findings and verify the results. Likewise, a survey of the call center training module to cross-check the apology strategies taught to trainees was also performed. 


\section{Results/Findings and Discussion}

The tables below present the data which were gathered through a Discourse Completion Task (DCT). The respondents' answers were then coded and categorized.

Table 1

Apology Strategies Used by Call Center Agents

\begin{tabular}{lcc}
\hline \multicolumn{1}{c}{ Apology Strategies } & Frequency & Percent \\
\hline Offering repair & 739 & 32.34 \\
\hline Expression of apology & 560 & 24.51 \\
\hline Promise of follow-up action & 302 & 13.22 \\
\hline Empathy & 165 & 7.22 \\
\hline Showing concern & 162 & 7.09 \\
\hline Repetition of complaints & 67 & 2.93 \\
\hline Explanation & 63 & 2.76 \\
\hline Gratitude & 53 & 2.32 \\
\hline Promise of forbearance & 45 & 1.97 \\
\hline Making a suggestion & 45 & 1.97 \\
\hline Acknowledgment of responsibility & 43 & 1.88 \\
\hline Giving the time frame for action & 41 & 1.79 \\
\hline All Strategies Combined & 2,285 & 100 \\
\hline
\end{tabular}

The table shows the different types of apology strategies used by call center agents. The data analysis was initially done by using the strategies formulated by Cohen et al. (1986 in Jones, 2012, p. 104). However, the coding process and data analysis were enhanced using the categorization of apology strategies used by Prachanant (2016) in his study on how to respond to complaints in the hotel business. Thus, the researchers were able to code 12 semantic formulas, which are arranged according to frequency count as they occur in the agents' responses.

Cohen et al. (1986 in Jones, 2012, p. 104) presented five verbal apology strategies such as an expression of apology (I'm sorry); an explanation or account of the situation (We are processing so many orders this week...); an acknowledgment of responsibility (It is our fault...); an offer of repair (How can I make it up to you?), and a promise of forbearance (It will never happen again). According to Jones (2012), it takes one or two apology strategies to be considered a good apology. On the other hand, he emphasized that an utterance can be considered a perfect apology if it has the five specified semantic formulas.

Since this study revolves around inbound calls, it is expected that most calls are requests and complaints call from customers. Inbound calls are phone calls initiated by customers to a 
company's customer service. Most customer service teams' primary function is to enhance the customers' experience. According to Belfas \& Musyahda (2015), customer service is part of public service. Therefore, she emphasized that "apology strategies are needed in the public services to face a customer's complaint."

The CEO, one of the biggest call centers in the Philippines, emphasizes that the first concession, something done or agreed upon to reach an agreement or improve a situation, is an apology. In his statement, their company's data scientist found out that material concessions in the form of gifts and discount coupons do not guarantee loyalty and satisfaction from the customers.

Table 2

Patterns of Semantic Formulas Used by Call Center Agents

\begin{tabular}{ll}
\hline \multicolumn{1}{c}{ Apology Strategies } & Frequency \\
\hline Expression of apology + offering repair & 1,299 \\
\hline Offering repair + promise of follow-up action & 1,041 \\
\hline Empathy + offering repair & 904 \\
\hline Offering repair + showing concern & 901 \\
\hline Expression of apology + promise of follow-up action & 862 \\
\hline Repetition of complaints + offering repair & 806 \\
\hline Explanation + offering repair & 802 \\
\hline Offering repair + gratitude & 792 \\
\hline Expression of apology + repetition of complaints & 788 \\
\hline Offering repair + promise of forbearance & 784 \\
\hline Offering repair + suggestions & 784 \\
\hline All Strategies Combined & 9,763 \\
\hline
\end{tabular}

The data show that the semantic formulas of expressing apology and offering repair combined have been identified as the highest number of utterances incurred. This phenomenon may be attributed to a characteristic of the Filipino call center agents, which is overly apologetic. Aside from this, the agents are too focused on the technical part in finding solutions or repairs to the customer's problem that they forget to build a personal emotional connection with the customer. This means that each agent has to make the client well taken care of and properly address his/her concerns. 


\section{Conclusion \& Discussion}

The analysis of data was done using the following theories: Goffman's (1971) Descriptions of Apology, Olshtein \& Cohen's (1983) Classification of Apology, Prachanant's (2006) Apology Strategies, and Cohen et al. (1986) Verbal Strategies. However, it was found out that Prachanant's (2006) model provided the most comprehensive and highly applicable description of the data; thus, coding and analysis of data primarily followed the descriptions of Prachanant (2006).

The researchers were able to code 12 semantic formulas, which are arranged according to frequency count as they occur in the agents' responses. According to Jones (2012), a "good apology" requires one or two apologetic tactics. On the other hand, Cohen et al. (1986 in Jones, 2012) emphasized that an utterance can be considered a perfect apology if it has met all of the following: expression of apology, explanation or account of the situation, acknowledgment of responsibility, an offer of repair, and promise of forbearance.

The data show that the semantic formulas of expressing apology and offering repair combined have been identified as the highest number of utterances incurred. According to the CEO of one of the biggest call centers in the Philippines, this phenomenon may be attributed to a characteristic of the Filipino call center agents, which is overly apologetic. The agents are too focused on the technical part in finding solutions or repairs to the customer's problem that they forget to build a personal emotional connection to the customer.

According to the data, Filipino call center agents have effectively created "perfect apologies" by employing all five Cohen et al. (1986) tactics in the majority of their complaint calls. However, the sequence is distorted by emphasizing more on offering a repair.

The acts of apology of the respondents are rather mechanical than sincere due to the scripts, spiels, and training agents get from the management prompting them to limit their apologies by the book. Due to the lack of personal emotional connections between the agent and the client, the former usually give away concessions rather than provide assurance.

\section{Recommendations}

Based on the findings of this study, the researchers would like to recommend that call center training on apology be emphasized on building personal connections rather than on structuring mechanical responses to situations. Second, a study on how clients react or respond to acts of apology by customer associates be done to delineate the acts of apology and their perlocutionary effects on the client. Finally, concerning the second recommendation, another study on what constitutes a felicitous apology in customer service be done to increase apologizing effectiveness in customer relations. 


\section{References}

Austin, J. L. (1975). How to do things with words (2nd ed.). Massachusetts: Harvard University Press. Retrieved from https://www.ling.upenn.edu/ rnoyer/courses/103/Austin.pdf

Belfas, N. N., \& Musyahda, L. (2015). A study of apology strategies used by customer service officers in Telkomsel Surabaya. Anglicist Volume,4(1), 41-45. Retrieved from http://journal.unair.ac.id/ANGLICIST@a-study-of-apology-strategies-used-bycustomer-service-officers-article-9877-media-94-category-8.html

Bowens, T., \& Cook, E. (n.d.). 27 English Phrases for a Positive Call Center Experience. Retrieved August 30, 2021, from https://www.fluentu.com/blog/business-english/callcenter-english/

Brown, J. G. (2003). The role of apology in negotiation. Marq. L. Rev., 87, 665. Retrieved from JG Brown - hawaii.edu

Business process outsourcing in the Philippines. (2017). ASEAN Briefing. https://www.aseanbriefing.com/news/business-process-outsourcing-philippines/

Cabigon, M. (2015). State of English in PH: Should we be concerned? Philippine Daily Inquirer. Retrieved from https:/opinion.inquirer.net/90293/state-of-english-in-phshould-we-be-concerned

Cook, G. (1989). Discourse. Oxford University Press.

Formal and informal language. (2020). University of Technology Sydney. https://www.uts.edu.au/sites/default/files/article/downloads/Formal and Informal Language.pdf

Gubin, A. (2014). You ' re sorry, but do you really care? :: Apologies, power and interpersonal relationships. (Unpublished master's thesis). University of Massachusetts Amherst. Retrieved from https://scholarworks.umass.edu/cgi/viewcontent.cgi article=3487\& context=theses

Jones, R. H. (2012). Discourse Analysis: A resource book for students. Abingdon, Oxon: Routledge.

Kort, L. F. (1975). What is an apology? Retrieved from https://pdfs.semanticscholar.org/dc0d/9eddd955dbfb79e51ed9cd2add8d19043104.pdf

Lockwood, J., Forey, G., \& Price, H. (2008). Englishes in the Philippine business processing outsourcing industry: issues, opportunities and initial findings. In M. L. Bautista \& K. Bolton (Eds.), Philippine English: Linguistic and Literary Perspectives. Hong Kong University Press.

https://www.academia.edu/21443463/Englishes_in_the_Philippine_Business_Processin g_Outsourcing_Industry_issues_opportunities_and_initial_findings 
Luu Le Phuong Thanh, Qui, N. T. N., Thanh, V. N. T., \& Hung, N. M. T. (2021). The need of applying English learning apps to help Van Lang University students improve their spoken English performance. AsiaCALL Online Journal, 12(2), 72-86.

https://asiacall.info/acoj/index.php/journal/article/view/33/22

McGaan, L. (2010). Why study communication? Comm 101-Fundamentals of Communication. https://department.monm.edu/cata/mcgaan/classes/cata101/why-studycomm.htm

Ogiermann, E. (2018). Discourse completion tasks. In W. B. Andreas H. Jucker, Klaus P. Schneider \& Authors: (Eds.), Methods in Pragmatics (Handbooks of Pragmatics 10). de Gruyter Mouton. https://doi.org/10.1515/9783110424928-009

Olshtain, E., \& Cohen, A. (March 1990). The learning of complex speech act behaviour. TESL Canada Journal, 7(2), 45-65. Retrieved from https://files.eric.ed.gov/fulltext/EJ407136.pdf

Parker, F., \& Riley, K. (2010). Linguistics for non-linguists: A primer with exercises. Pearson Education, Inc.

Pham, N. T. L. (2021). American English and Vietnamese use in public signs: a pragmatic cultural comparison and translation. International Journal of TESOL \& Education, 1(3), 14-36. http://i-jte.org/index.php/journal/article/view/79/21

Porteous, C. (2020). The secret to a successful business is happy customers. Entrepreneur Asia Pacific. https://www.entrepreneur.com/article/342677

Prachanant, N. (2006). Pragmatic transfer in responses to complaints by Thai EFL Learners in the hotel business (Unpublished doctoral thesis). Surunaree University of Technology. Retrieved from http://sutir.sut.ac.th:8080/sutir/bitstream/123456789/2486/1/nawamin_fulltext.pdf

Prachanant, N. (2016). A cross-cultural study of apology speech act realizations. International Journal of Languages, Literature and Linguistics. 146-151. DOI: 10.18178/IJLLL.2016.2.3.85

Searle, J. R. (1979). Expression and Meaning: Studies in the theory of speech acts. New York: Cambridge University Press. Retrieved from en.bookfi.net

Sienes, M. J. (2019). Discourse analysis of speech acts of thanking by Bahraini and Vietnamese ESL learners. Silliman Journal, 60(1), 81-104.

Slocum, D. J., Allan, A., \& Allan, M. M. (2011). An emerging theory of apology. Edith Cowan University Research Online. Retrieved from https://ro.ecu.edu.au/ecuworks2011/280/

Spierer, M. J. (1976). Goffman's model of remedial interchanges: an empirical evaluation. Retrieved from https://www.elibrary.ru/item.asp?id=7134000 
Ugla, R. L., \& Abidin, M. J. (March 2016). A study of apology strategies used by Iraqi EFL university students. International Journal of Evaluation and Research in Education (IJERE), 5(1), 32-38. Retrieved from https://files.eric.ed.gov/fulltext/EJ1094582.pdf

\section{Biodata}

Mary Joy Vailoces Sienes is an ESL Teacher at Vinschool Secondary School, Times City, Hanoi, Vietnam. She is currently in a residency program of her Ph. D in English with a concentration in TESOL at Silliman University, Dumaguete City, Philippines. Her interest includes qualitative research, especially in the line of pragmatics and discourse analysis.

Jasper Eric C. Catan currently sits as the Director for Research and Extension Services of Foundation University, Dumaguete City, Philippines. His areas of interest are language pedagogy research, education policy research, service-learning research, and physical and mental health research. 